\title{
Drug Demand Prediction Model Using Adaptive Neuro Fuzzy Inference System (ANFIS)
}

\author{
Amir Mahmud Husein \\ Universitas Prima Indonesia \\ Medan, Indonesia \\ amirmahmud@unprimdn.ac.id
}

\author{
Allwin M Simarmata \\ Universitas Prima Indonesia \\ Medan, Indonesia \\ allwinsimarmata@unprimdn.ac.id
}

\begin{abstract}
Drug planning is the process of activities in the selection of types, quantities, and prices in accordance with the needs and budget for the coming procurement period in order to avoid the occurrence of excess or emptiness of drug supplies when needed by patients. Management of planning that is not optimal drug needs will have a negative impact on hospitals, both medically and economically, because $50-60 \%$ of the total budget used for treatment and medical equipment, uncertainty of drug needs due to disease population and the number of patients can change according to conditions the volume of patient diagnostic data, thus requiring an automatic way to select drug needs according to disease progression. This study aims to create a prediction model for drug needs with the ANFIS method, the data analysis framework used is sourced from drug usage / sales data at the Royal Prima Hospital 2016-2017 by building a software that implements the ANFIS method. Stages of application testing are carried out by applying the previous year's data to predict the current year, namely the 2016 data for 2017 predictions, while the 2017 data for 2018 predictions. The data source will be used to analyze the ANFIS membership function that generates parameters for the ANFIS method in training and testing data. The results of the analysis of the ANFIS parameters will be updated to produce a small error value (close to 0), based on the value of Root Mean Square Error (RMSE), then an evaluation is carried out with a quantitative and qualitative analysis of the predicted results with the existing system.
\end{abstract}

Keywords - ANFIS method, Drug Demand Prediction, RSU Royal Prima

\section{INTRODUCTION}

Hospital is one of the healing and health recovery facilities for patients (DeKes RI, 2004). Medicine is a good need for sick people, $50-60 \%$ of the overall hospital budget is used for medication and medical equipment. Management of drug handling that is not optimal will have a negative impact on hospitals both medically and economically. Good drug management guarantees the availability of drugs whenever needed, in sufficient quantities and guaranteed quality, to support quality services in hospitals (Satibi, 2014).

Drug planning is a process of activity in the selection of types, quantities and prices of drugs that are in accordance with the needs and budget for the coming procurement period, to avoid the occurrence of excess or emptiness of drug stocks when needed by patients (Satibi 2014), so it is necessary to plan optimal drug needs for choose drugs that are really needed for most populations based on the patient's disease pattern.

\section{Literature ReVIEW}

Economic Order Quantity Method (EOQ is one of the inventory control techniques, it is easy to use but is based on several assumptions, namely: demand is known and is constant, time between order and receipt, known and constant, demand is received immediately, no discount, cost what happens is that only the set-up fee for ordering is known and is constant, there is no out of stock, but the model does not involve the uncertainty of the number of disease populations and the number of patients (Husein, Budhiarti \& Mawengkang, 2012).

Uncertainty of drug needs is due to disease population and the number of patients can change according to the condition of the patient's diagnostic data volume, thus requiring an automatic way to 
choose the drug needs according to disease development (Mawaddah, et all 2018). Adaptive Neuro Fuzzy Inference System (ANFIS) is an algorithm that combines fuzzy systems with artificial neural networks. ANFIS method can be used for forecasting or prediction (Agrawal S., Jindal, M., Pillai, G. N, 2010), (Verse, S., Khosravanian, A. 2014), because it has a high degree of accuracy (Makridou, G ., Atsalakis, GS, \& Zopounidis, C, 2013). Some researchers apply the ANFIS method for predictions, such as weather prediction (Dewi, Kartikasari \& Mursityo, 2014), Fluctuations in Water Levels of Reservoirs (Piri \& Kahkha, 2016), unemployment rates (Dewi \& Himawati, 2015), inventories (Paul, SK, Azeem, A., \& Ghosh, AK 2015), stock prices (Nhu, NH, Nitsuwat, S., Sodanil, M, 2013), but having a dependency on membership functions has a significant effect on the prediction results, so it is necessary to analyze ANFIS parameters (Husein, et all 2018).

From the results of several studies, the ANFIS method is proposed by applying the Root Mean Square Error (RMSE) method to measure the accuracy of the prediction of drug needs at Royal Prima Hospital Medan, so that it is expected that the method produces an optimal model of drug demand prediction. Accurate prediction results will greatly affect decision making and avoid excess or emptiness of drug stocks to improve medical services, in addition to a more optimal drug needs budget.

\section{PROPOSED METHOD}

In this section, a proposed model is proposed to optimize the prediction of optimal drug needs in a hospital, as shown in Figure 1.

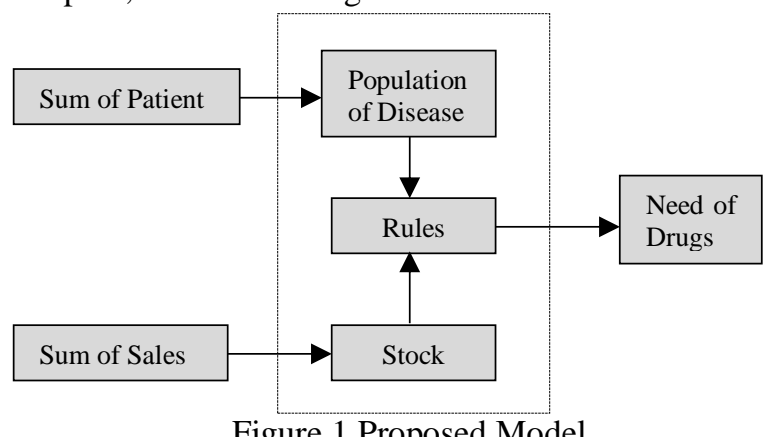

In the figure above, the dataset used is sourced from the number of patients, then the stages of disease population classification are carried out to form the ANFIS method rules, then the next data source is from the amount of stocking and stock, both of these data sources will be applied to the ANFIS method so as to produce a prediction of drug needs based on classification disease, the number of sales and stock of drugs available, the final results are expected to facilitate the leadership in making plans for drug needs.

\section{Test the proposed model}

In this study we propose 2 (two) methods to be applied to the proposed model for prediction of drug needs.

A. Adaptive Neuro-Fuzzy Inference System (ANFIS)

ANFIS is a Neuro-Fuzzy approach which was introduced by Jang (Jang et all 1997,1993) which is confronted with the Takagai and Sugeno fuzzy system models (1985) and can be used for control, prediction or forecasting applications. ANFIS architecture is the same as a neural network with radial functions with some specific limitations. Neural network learning process is used to optimize the value of fuzzyfication parameters. In NeuroFuzzy consists of five layers of processes. At layer 1 parameter is the fuzzy set membership function parameter that is nonlinear to the system output. The learning process on parameters uses a Reverse Propagation error (EBP) to update parameter values. At the 4th layer, the parameters are linear parameters to the system output that compiles the fuzzy prize base. In the 4th layer, the Least-Squares Estimotor (LSE) method is used as in Figure 2.

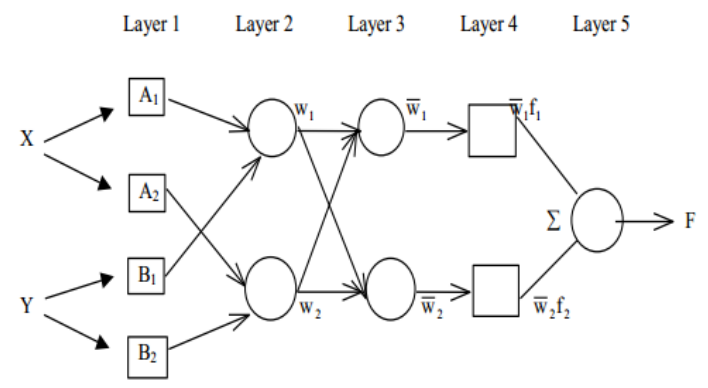

Figure 2 ANFIS network architecture (Jang et all, 1997,1993)

The learning phase of the ANFIS method is as follows:

layer 1: Each node in this layer is an adaptive node with a node

$\mathrm{O}_{1, \mathrm{i}}=\mu \mathrm{A}_{\mathrm{i}}(\mathrm{x})$ untuk $\mathrm{i}=1,2$

$\mathrm{O}_{1, \mathrm{i}}=\mu \mathrm{B}_{\mathrm{i}-2}(\mathrm{x})$ untuk $\mathrm{i}=3,4$ 
Where $\mathrm{x}, \mathrm{y}$ is the input node $\mathrm{i}$ and $\mu \mathrm{Ai}$ and $\mu \mathrm{Bi}-2$ are linguistic values. $O 1, i$ is the degree of membership of the fuzzy set $\mathrm{T}(\mathrm{A})=\{\mathrm{A} 1, \mathrm{~A} 2, \mathrm{~B} 1, \mathrm{~B} 2\}$ where $\mathrm{A} 1$, A2, B1, B2 are linguistic variables. The membership function used is gbell.

$$
\mu_{A i}(x)=\frac{1}{1+\left\{\left(\frac{x-c_{i}}{a_{i}}\right)\right\}^{b_{i}}}
$$

Layer 2: The multiplication operator of the fuzzy rule at this node is AND.

$\mathrm{O}_{2, \mathrm{i}}=\mathrm{w}_{\mathrm{i}}=\mu \mathrm{A}_{\mathrm{i}}(\mathrm{x}) \cdot \mu \mathrm{B}_{\mathrm{i}}(\mathrm{y})$ for $\mathrm{i}=1,2$

With wi is the activation path at the i-node Layer 3: the i-th node counts the ratio of the $\mathrm{i}$-th degree membership rule to the number of membership degree rules.

$$
O_{3, i}=\bar{w}_{i}=\frac{w_{i}}{w_{1}+w_{2}}, \quad \text { by } \mathrm{i}=1,2
$$

Layer 4: each layer in this layer is an adaptive node

$$
O_{4, i}=w_{i} f_{i}=w_{i}\left(p_{i} x+q_{i} y+r_{i}\right)
$$

Layer 5: is a single node that calculates output by summing all input signals

$$
O_{5, i}=\sum \bar{w}_{i} f_{i}=\frac{\sum_{i} w_{i} f_{i}}{\sum_{i} w_{i}}
$$

\section{K-Means Clustering}

$\mathrm{K}$-means clustering is one of the most popular clustering algorithms used because it has a simple algorithm that is easy to implement and efficient in its complexity [5]. Algortima KMeans determines the cluster of objects based on the attributes / features of the object into the cluster (K). The groups are distinguished by their center. This algorithm is very sensitive to the initial cluster center value placement. Determination of the partition number of clusters (k) is very important in this algorithm, but there are no provisions that apply to determine the number of clusters (k) formed [34]. The steps in the K-means algorithm are as follows:

1. Prepare training data.

2. Set K cluster value.

3. Set the initial value of centroids.
4. Calculate the distance between data and centroid using the formula (Euclidean Distance).

5. Data partitioning is based on a minimum value.

6. Then iterate as long as the data partition is still moving (no more moving objects to another partition), if it is still then go to point 3 .

7. If the current data group is the same as the previous data group, then stop iteration.

8. Data has been partitioned according to final centroid values.

\section{Stages of Model Implementation}

Good drug management guarantees the availability of drugs whenever needed, in sufficient quantities and guaranteed quality, to support quality services in hospitals. The goal of drug management in a hospital is that the required drugs are available at all times when needed, in sufficient quantities, guaranteed quality and affordable prices to support quality services. One function of drug management is the selection of drugs that are really needed for most populations based on existing disease patterns. The selection process is a very decisive start in drug planning because through drug selection will be reflected in how many drug items will be consumed in the future. Drug planning is a process of activity in the selection of types, quantities and prices of drugs that are in accordance with the needs and budget for the coming procurement period.

From the results of observations for drug planning in public and private hospitals. The drug planning process at a government hospital is based on collecting drug needs data from medical service fields such as polyclinics, radiology, pharmacology and others. Drug needs data will be collected in the logistics section to be submitted to the drug planning section, the planning section conducts the drug needs selection for the next one year. however, the drug planning budget is not based on needs because the budget proposed by the hospital can change according to the results of a meeting with parliament and the hospital director's decision. Data on drug needs from the fields of medical services does not make a reference, and drugs that enter hospitals are not necessarily in accordance with needs. Budget 
dependency causes planning to not run well, and results in frequent drug shortages and excesses.

In private hospitals, the planning process relies more on sales data, stock and experience of the head of IFRS, but is still considering the proposed drug needs in the field of medical services. Drug planning cannot run well due to the absence of the latest formulary so that there are no restrictions on the number and type of drugs, the lack of budget planning for bill payments and drug procurement in the short and long term, the small role of doctors, the discount factor from suppliers causes excess in purchasing drug because it is not in accordance with the needs and the length of time for making a drug stock report card from the field of medical services.

The conclusion from interviews with hospital leaders, the head of IFRS and the head of the pharmacy is the difficulty in getting data on the frequency of patient visits, disease patterns, patient age, drug use and stock available so that following the drug planning method will require a long time, while patients need medication according to the doctor's prescription. The unavailability of drugs in hospitals makes patients prefer to buy drugs to foreign pharmacies.

\section{Data obtained}

Table 1 Sample data for 2015

\begin{tabular}{|c|c|c|c|c|c|c|c|c|c|c|c|c|c|}
\hline \multirow{2}{*}{ Nama Obat } & & & & & \multicolumn{4}{|c|}{ TAHUN 2015} & & & & \multicolumn{2}{|c|}{ JUMLAH } \\
\hline & 1 & & 3 & & 5 & 6 & & 8 & & 10. & 11] & 12 & 78 \\
\hline ACILAZ 30 MG KAPSUL & 371 & 2 & 2 & 2 & 9 & & 14 & 18 & 33 & 33. & 7 & ${ }_{11}$ & 504 \\
\hline ACYCLOVIR $400 \mathrm{MG}$ TABLET & 34. & & 456 & 17 & & 59 & & 24 & 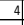 & & 149 & & 1073 \\
\hline ACYCLOVIR 5\% CREAM & 14 & & & 142 & 315 & & 123 & 257 & 140 & 10 & & 9 & 1028 \\
\hline ALBOTHYL GEL & & 16 & 16 & 4 & & 240 & & & & 264 & & 151. & 808 \\
\hline ALBUMINAR 25\% 100 ML INEKSI & 20 & 1 & 1 & 88 & 57 & & & 42 & 124 & 24 & 71 & 18. & 459 \\
\hline ALCO ORAL 15 ML DROPS & 1 & 5 & 80 & 15 & 1 & 15 & 52 & 1 & 17 & 77 & 8 & 12 & 284 \\
\hline AUNAMIN F INEKSI & 45 & 1 & 75 & 29 & 7 & 30 & 1 & 1 & 14 & 179 & 36 & 58 & 476 \\
\hline AUNAMIN F TABLET & 2 & 74 & 4 & 7 & 14 & & 13 & 63 & 78 & & 169 & 2 & 435 \\
\hline ALLUPURINOL $100 \mathrm{MG}$ TABLET & 6 & t & 2 & 51 & 117 & 14 & & & 199 & & 40. & & 609 \\
\hline ALLUPURINOL 300 MG TABLET & 11 & 1 & 4 & 10 & 2 & 139 & 120 & & & 12 & 10 & 28 & 341 \\
\hline ALPRAZOLAM 0.5 MG TABLET & 199 & 13 & 6 & 7 & 3 & 13 & 6 & 1 & 4 & 8 & 4 & \begin{tabular}{|c|}
103 \\
\end{tabular} & 367 \\
\hline ALPRAZOLAM 1 MG TABLET & 13 & 322 & 1 & 4 & 11. & 2 & 2 & 2 & 28 & 75 & 2 & 53 & 515 \\
\hline AMARYL3MG TABLET & 3 & 18 . & 5 & 1 & 1 & 8 & 32. & 8 & 84 & 6 & 19 & 2 & 187] \\
\hline AMARYL M 1/250 MG TABLET & 4 & & 110 & 2 & 28 & 7 & & 50 & & 1 & & 24 & 254 \\
\hline AMARYL M 2/500 MG TABLET & & 56 & 7 & 2 & & 95 & 17 & 9 & & 12. & 82 & & \\
\hline AMBROXOL 60 ML SIRUP & 21 & & 4 & & 13 & & 17 & 29 & & 222 & & 160 & 286 \\
\hline AMINERON TABLET & 66 & 5 & 14 & 41 & 29 & & 422 & 21 & & 639 & 25 & & 1329 \\
\hline$\overline{\text { AMINOFLIID } 1000 \mathrm{MLINFUS}}$ & 4 & 23 & 286 & 6 & 29 & 57] & 24 & 716 & 360 & $\mid 13$. & 5 & $|43|$ & 1566 \\
\hline AMINOFLUID 500 MG INFUS & 4 & 2 & 69 & 7 & & 331 & 19 & 41 & 182 & 13 & 5 & 479 & 1153 \\
\hline AMINOFUSIN HEPAR INFUS & 10 & 9 & 17 & 251 & 339 & 101 & 2 & 5 & 33 & 124 & 516 & 97 & 1504 \\
\hline AMINOFUSIN PAED 250 MLINF & 4 & 11 & 1 & 59 & 79 & & 83 & 48 & 82 & 81 & 14 & \begin{tabular}{|l|l}
56 \\
\end{tabular} & 523 \\
\hline AMINOPHILN 24 MG INJEKSI & & 3 & 92 & & & 40 & 60 & & & 184 & & \begin{tabular}{|c|}
97 \\
\end{tabular} & 560 \\
\hline
\end{tabular}

Table 2 Sample data for 2016

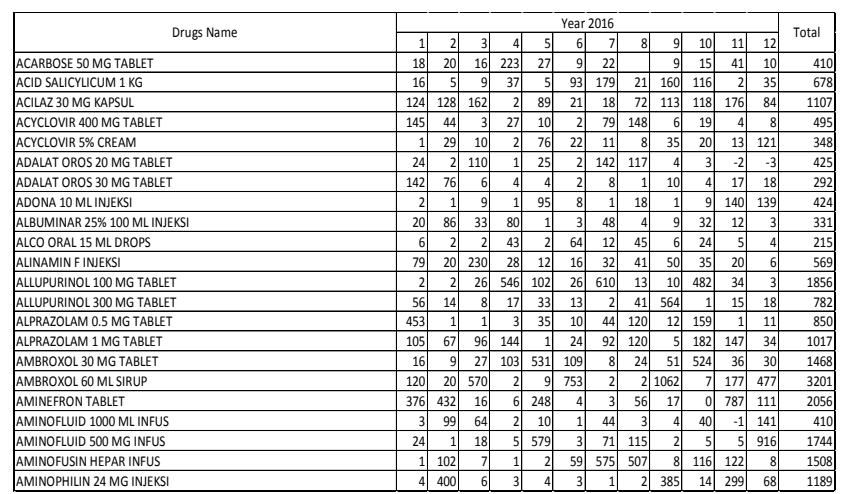

The data needs for ANFIS training and testing are sourced from the previous year's data obtained from actual data in 2015 and 2016 at one of the hospitals in Medan. Input data for 2015 will be used for predictions in 2016 and compare the results of ANFIS predictions with actual data in 2016 and so on until the comparison of predictions for 2017 with actual data for 2017.

\section{RESULT AND DISCUSSION}

Training and testing in the first approach directly apply the ANFIS method to the data source with five input indicators namely gender, patient age, diagnosis code, length of stay, stock, and one output. There are 34 rules that are used in the ANFIS Sugeno Order one model. In the first stage is looking for learning rates for optimal learning. This test uses the amount of training data as much as $50 \%$ of the total data.

Tabel 3. Learning Rate

\begin{tabular}{|r|c|}
\hline Learning rate & RMSE \\
\hline 0,001 & 0,47542 \\
\hline 0,002 & 0,49789 \\
\hline 0,003 & 0,47943 \\
\hline 0,004 & 0,08513 \\
\hline 0,005 & 0,26143 \\
\hline 0,006 & 0,93914 \\
\hline 0,007 & 0,21528 \\
\hline 0,008 & 0,84704 \\
\hline 0,009 & 0,14502 \\
\hline & \\
\hline
\end{tabular}




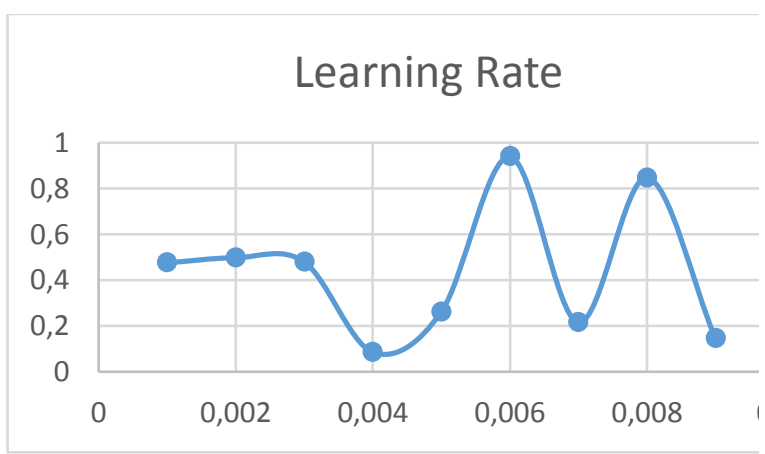

Picture 3. Learning Grate Graphic

Based on table 3, that the value of the RMSE larning rate tested is very well below the number one, but the smallest RMSE value produced is 0.004 . The smallest RMSE value will be used for RMSE testing and accuracy with a combination of training data and test data. For testing RMSE and accuracy in training used $85 \%$ of the total amount of data. For testing data used $70 \%$ of the total amount of data. Each data combination was repeated ten times to retrieve the RMSE value and accuracy of the test results. The results of training and testing can be seen in Figure 4 and Figure 5.

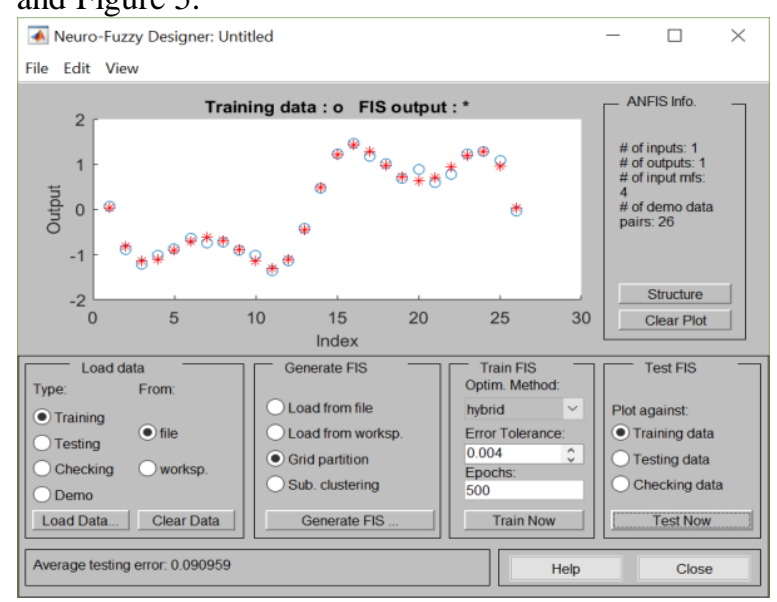

Picture 4. Training

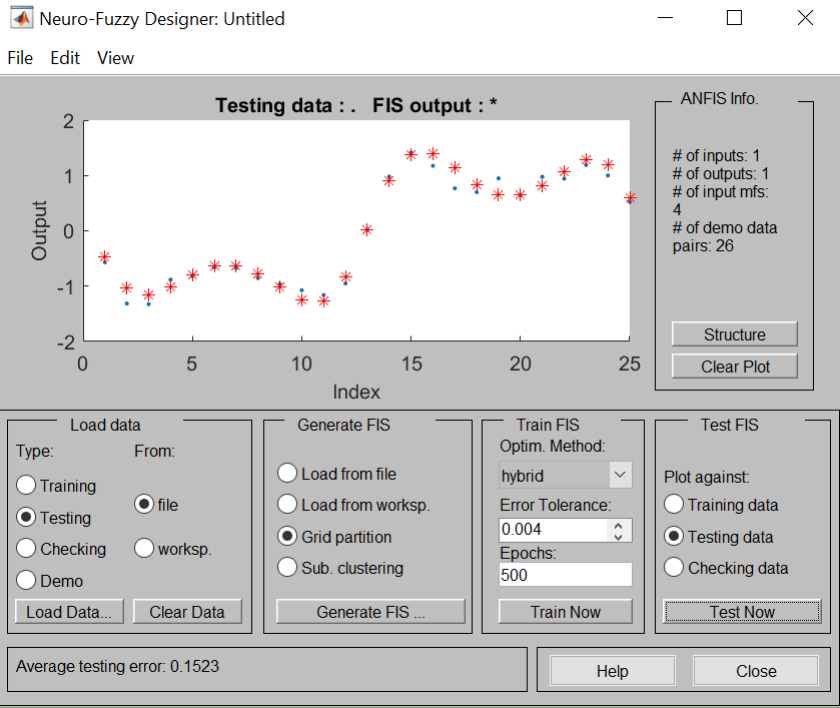

Figure 5. Testing

In Figure 4 the results of training data are $80 \%$ of the total data, with an error value of 0.004 , epoch 500 , the results of the training will be used as a test for the prediction of drug needs with an error of 0.004 , the epoch 500 test results are shown in table 4 for predictions of 2016 and year needs 2017.

Table 2. Prediction year 2016 and year 2017

\begin{tabular}{|c|c|c|c|c|c|c|}
\hline Drugs Name & $\begin{array}{l}\text { Actual } \\
2016 \\
\end{array}$ & $\begin{array}{c}\text { Prediction } \\
2016 \\
\end{array}$ & RMSE & $\begin{array}{c}\text { Actual } \\
2017 \\
\end{array}$ & $\begin{array}{c}\text { Prediction } \\
2017 \\
\end{array}$ & RMSE \\
\hline 1 |ACID SALCYLICUM $1 \mathrm{KG}$ & 410 & 414 & 0,816 & 1521 & 1524 & 0,612 \\
\hline 2 ACILAZ 30 MG KAPSUL & 678 & 734 & 1,880 & 131 & 132 & 0,034 \\
\hline 3 ACTOSMET TAB 15 MG & 1107 & 1105 & 0,067 & 475 & 478 & 0,101 \\
\hline $\begin{array}{l}\text { A ADONA } 10 \text { ML INJEKSI } \\
\end{array}$ & 495 & 345 & 5,037 & 1241 & 1239 & 0,067 \\
\hline 5 ALBOTHYL CONCENTRATE $10 \mathrm{ML}$ & 348 & 298 & 1,679 & 267 & 342 & 2,518 \\
\hline 6 ALBUMINAR 25\% 100 ML INJEKSI & 734 & 731 & 0,101 & 224 & 234 & 0,336 \\
\hline 7 ALCO ORAL 15 ML DROPS & 425 & 434 & 0,302 & 205 & 210 & 0,168 \\
\hline 8 ALINAMIN F INJEKSI & 292 & 289 & 0,101 & 112 & 119 & 0,235 \\
\hline 9 ALLUPURINOL 100 MG TABLET & 424 & 456 & 1,074 & 167 & 165 & 0,067 \\
\hline 10 ALLUPURINOL 300 MG TABLET & 215 & 211 & 0,134 & 291 & 289 & 0,067 \\
\hline 11 ALPRAZOLAM 0.5 MG TABLET & 569 & 561 & 0,269 & 94 & 121 & 0,907 \\
\hline 12 ALPRAZOLAM 1 MG TABLET & 1856 & 1923 & 2,250 & 328 & 327 & 0,034 \\
\hline \begin{tabular}{l|l|l|l|}
13 & AMBROXOL 30 MG TABLET \\
\end{tabular} & 1400 & 1398 & 0,067 & 838 & 829 & 0,302 \\
\hline 14 AMBROXOL 60 ML SIRUP & 782 & 734 & 1,612 & 642 & 649 & 0,235 \\
\hline 15 AMINEFRON TABLET & 850 & 852 & 0,067 & 184 & 184 & 0,000 \\
\hline 16 AMINOFLUID 1000 ML INFUS & 1017 & 1020 & 0,101 & 383 & 389 & 0,201 \\
\hline 17 AMINOFLUID 500 MG INFUS & 1468 & 1470 & 0,067 & 229 & 229 & 0,000 \\
\hline 18 AMINOFUSIN HEPAR INFUS & 2519 & 2515 & 0,134 & 545 & 534 & 0,369 \\
\hline 19 AMINOPHILIN 24 MG INJEKSI & 3201 & 3207 & 0,201 & 742 & 765 & 0,772 \\
\hline 20 AMINOSTERIL INFANT 6\% & 2056 & 2051 & 0,168 & 386 & 398 & 0,403 \\
\hline \begin{tabular}{|l|l|}
21 & AMITRIPTYLINE TABLET \\
\end{tabular} & 410 & 420 & 0,336 & 640 & 612 & 0,940 \\
\hline \begin{tabular}{|l|l|}
22 & AMLODIPINE 5 MG TABLET \\
\end{tabular} & 1744 & 1740 & 0,134 & 276 & 198 & 2,619 \\
\hline 23 AMLODIPINE BESYLATE 10 MG TABU & 1508 & 1510 & 0,067 & 468 & 412 & 1,880 \\
\hline 24 AMLODIPINE BESYLATE 10 MG TABU & 1339 & 1339 & 0,000 & 163 & 172 & 0,302 \\
\hline 25 AMOXAN 500 MG KAPSUL & 487| & 490 & 0,101 & 353 & 311 & 1,410 \\
\hline
\end{tabular}

In the table above is the result of testing $70 \%$ of the data from the total amount of data for the prediction of drug needs in 2016 using 2015 data, while in 2017 using the 2016 data. Overall the prediction results for drug needs in 2016 and 2017, 
the ANFIS method is accurate based on comparison of values predictions with actual data, but there are still data on RMSE values above 0, the average RMSE value of 0.0669 for predictions in 2016 and 0.0594 for predictions for 2017. The graph of prediction results is seen in Figure 6.

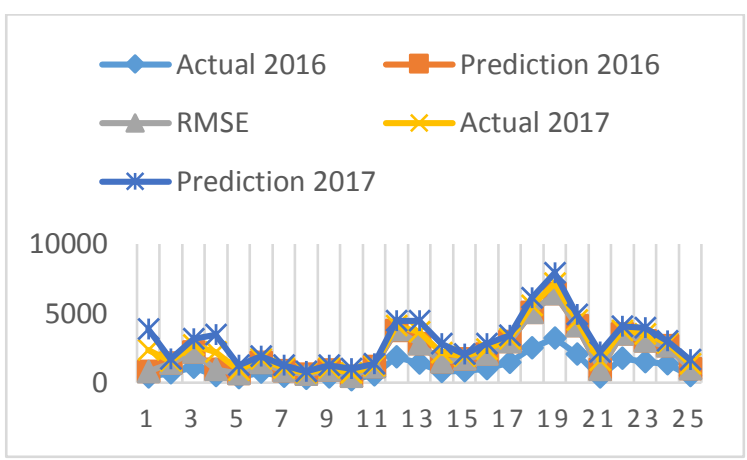

Picture 6. Graphic prediction year 2016 and year 2017

\section{Suggestion}

Based on the results of testing using patient medical data in 2015 and 2016, for the prediction of the need for drugs in 2016 and 2017, overall the ANFIS method is accurate in predicting this. But the testing phase still needs to be done using the K-Means classification method to optimize computational time so that it is more efficient

\section{ACKNOWLEDGMENT}

Thank you to:

1. Kemenristekdikti which has provided assistance in the form of financial support.

2. Universitas Prima Indonesia, which has provided motivational support and facilities.

3. Royal Prima Hospital, which has been prepared as a partner, provides a dataset.

\section{REFERENCES}

Abbasi E, and Abouec A, (2008). Stock Price Forecast by Using Neuro-Fuzzy Inference System. International Journal of Social, Behavioral, Educational, Economic, Business and Industrial Engineering Vol:2, No:10

Acheme, D. I., A. D., Rebecca, O. V., Olusegun, F., \& Isaac. O. (2014). A Predictive Stock Market Technical Analysis Using Fuzzy Logic.
Computer and Information Science; Vol. 7, No. 3; 2014. ISSN 1913-8989.

Agrawal S., Jindal, M., Pillai, G. N. (2010). Momentum Analysis based Stock Market Prediction using Adaptive Neuro-Fuzzy Inference System (ANFIS). Proceedings of the International Multi Conference of Engineers and Computer Scientists $2010 \mathrm{Vol}$ I, IMECS 2010. ISSN 2078-0958.

Agrawal, A., T., Ashtankar. P., S. (2013). An Expert System for Home Health Monitoring: The ANFIS Approach. International Journal of Scientific and Research Publications, Volume 3, Issue 7. ISSN 2250-3153.

Aggarwal, N., \& Aggarwal, K. (2012). Comparative Analysis of kmeans and Enhanced K-means clustering algorithm for data mining, International Journal of Scientific \& Eninnering Research, 3(3).

Ayat, S., Khosravanian, A. (2014). Identification and Classification of Coronary Artery Disease Patients using Neuro-Fuzzy Inference Systems. Journal of mathematics and computer Science 13 (2014) 136 - 141.

Babu, C. N., \& Reddy, B. E. (2014). A movingaverage filter based hybrid ARIMA - ANN model for forecasting time series data. Applied Soft Computing Journal, 23, 27-38.

Baihaqi S., et all. (2016). Comparison of Exponential Smoothing Methods in Forecasting Palm Oil Real Production. International Conference on Computing and Applied Informatics. doi:10.1088/1742-6596/801/1/012004

Bennett, C. J., Stewart, R. a., \& Lu, J. W. (2014). Forecasting low voltage distribution network demand profiles using a pattern recognition based expert system. Energy, 67, 200-212.

Bai, L., Liang, J., \& Dang, C. (2011). An initialization method to simultaneously find initial cluster centers and the number of clusters for clustering categorical data. Knowledge-Based Systems, 24(6), 785-795.

Billah, M., Waheed, S. (2015). Predicting Closing Stock Price using Artificial Neural Network and Adaptive Neuro Fuzzy Inference System (ANFIS): The Case of the Dhaka Stock Exchange. International Journal of Computer Applications (0975 - 8887). Volume 129 No.11.

Budiono, S., Suryawati, S., Sulanto, S.D. (1999). Manajemen Obat Rumah Sakit. Magister Manajemen Rumah Sakit. Fakultas Kedokteran UGM. Yogyakarta. 
Chen, H. H., Chen, M., \& Chiu, C. C. (2013). The Integration of Artificial Neural Networks and Text Mining to Forecast Gold Futures Prices. Communications in Statistics-Simulation and Computation, DOI:10.1080/03610918.2013.786780

Damayanti, A., Cahyadi, R. (2016). Algoritma Genetika Untuk Optimasi Struktur Anfis. Seminar Riset Teknologi Informasi (SRITI) tahun 2016.

Septiawan, F. Y., Dewa, C. K., Afiahayati. (2017). Prediction Of Currency Exchange Rate In Forex Trading System Using Genetic Algorithm. International Interdisciplinary Conference on Science Technology Engineering Management Pharmacy and Humanities Held on 22nd $-23^{\text {rd }}$. ISBN: 9780998900001

Ghosh, S., Dubey, K. S. (2013). Comparative Analysis of K-Means and Fuzzy C Means Algorithms. ((IJACSA) International Journal of Advanced Computer Science and Applications, Vol. 4, No. 4, 2013.

Hamasuna, Y., Endo, Y., \& Miyamoto, S. (2009). On tolerant fuzzy c-means clustering and tolerant possibilistic clustering. Soft Computing, 14(5), 487-494.

Hegazy, O., Soliman, S. O., \& Ahmed A. Toony, A. A. (2014). Hybrid of neuro-fuzzy inference system and quantum genetic algorithm for prediction in stock market. Issues in
Business Management and Economics Vol.2 (6), pp. 094-102. ISSN 2350-157X.

Husein, A. M., Mawengkang, H., Budiarthi, E. (2010), Teknik Fuzzy Inferences System Pada Manajemen Persediaan, Tesis: Megister Teknik Informatika Universitas Sumatera Utara, Sumatera Utara.

Izakian, H., \& Abraham, A. (2011). Fuzzy C-means and fuzzy swarm for fuzzy clustering problem. Expert Systems With Applications, 38(3), 1835-1838.

Lotfi, E., M.R. Karimi. M. R. (2014). OPEC Oil Price Prediction Using ANFIS. Journal of mathematics and computer science 10 (2014), 286-296.

Ji, Z., Sun, Q., \& Xia, D. (2011). Computerized Medical Imaging and Graphics A modified possibilistic fuzzy c -means clustering algorithm for bias field estimation and segmentation of brain MR image. Computerized Medical Imaging and Graphics, 35(5), 383-397.

Khan, Z. H., Alin, S. T., Md. Hussain, A. M. (2011). Price Prediction of Share Market using Artificial Neural Network (ANN). International Journal of Computer Applications (0975 - 8887) Volume 22- No.2.

A Robust Statistical Color Edge Detection for Noisy Images 2015 SemanticScholar

Adaptive technique for human face detection using HSV color space and neural networks 2009 National 